\title{
Zonas de contacto: los talleres de dramaturgia entre la última dictadura militar y la restauración democrática (1976-1985)
}

Eugenio Schcolnicov
CONICET/UBA, Argentina
eugeniobuzon@gmail.com

Fecha de recepción: 24/02/2021. Fecha de aceptación: 20/03/2021.

La política represiva ejecutada por la última dictadura militar instauró una profunda desarticulación del campo teatral y obligó a las prácticas escénicas y a los espacios de formación teatral a reinventar sus modos de producción y asociación. En este contexto, las intervenciones pedagógicas desarrolladas por autores como Osvaldo Dragún y Ricardo Monti resultaron decisivas para pensar la emergencia de nuevos procedimientos en materia de escritura teatral. Estas experiencias fundacionales tienen su continuidad en el desarrollo de los talleres de escritura teatral que se suceden durante el período democrático. En el siguiente artículo nos proponemos indagar en los procesos de enseñanza desarrollados por Ricardo Monti durante el gobierno de facto y en las propuestas de taller que se llevaron adelante dentro del ciclo Teatro Abierto 1985. Ambas instancias fueron eslabones significativos en el proceso de autonomización de los talleres de formación dramatúrgica respecto de los talleres de actuación y contribuyeron al reconocimiento de la escritura dramática como un tipo de disciplina portadora de saberes específicos.

PALABRAS CLAVE: RICARDO MONTI, TALLERES DE DRAMATURGIA, TEATRO ARGENTINO EN DICTADURA, TEATRO ARGENTINO EN POSDICTADURA.

\section{Contact Zones: Dramaturgy Workshops During the last Military Dictatorship and the Democratic Resumption (1976-1985)}

The political repression carried out by the last military dictatorship in Argentina produced a profound disarticulation of the theatre field, forcing stage practices and theatrical training spaces to reinvent their modes of production and association. In this context, the pedagogical interventions of authors such as Osvaldo Dragún and Ricardo Monti developed new procedures in the field of theater writing. These experiences were followed by the playwriting workshops that took place during the democratic period. In the following article we describe the teaching processes developed by Ricardo Monti during the military government and the workshop proposals carried out within the Teatro Abierto 1985. Both places became focal points in the process of autonomization of playwriting training from the drama training workshops and contributed to the recognition of playwriting 
as a type of discipline that carries a knowledge that's specific and different from that achieved in acting practices or stage directions learning.

KEYWORDS: RICARDO MONTI, PLAYWRIGHT WORKSHOPS, ARGENTINE THEATRE UNDER DICTATORSHIP, POSTDICTATORSHIP THEATRE IN ARGENTINA.

\section{Introducción}

En su ensayo Estética vs. poética, el filósofo Boris Groys (2018) diferencia dos perspectivas posibles a la hora de indagar en torno a los fenómenos artísticos: la actitud estética, construida desde la posición del espectador o el consumidor de arte, y la mirada poética, aquella que se centra en el productor artístico y sus "modos de hacer". Para Groys, el discurso de la modernidad ha instalado la perspectiva estética como el territorio privilegiado para pensar los objetos artísticos. Si bien el filósofo deja de lado la dimensión productiva inscripta en la experiencia estética (no reductible a un puro ejercicio contemplativo e interpretativo), es interesante considerar de qué manera esta dicotomía puede pensarse a la luz de la historiografía teatral. En este sentido, creemos que se vuelve necesario para el campo de la investigación escénica sistematizar una historia de las técnicas y de los procesos de trabajo en el campo teatral, así como también de las formas que han adquirido a lo largo del tiempo los espacios de intercambio y de circulación de sus saberes. Se trata, en definitiva, de tejer la trama que reconoce en los procesos productivos de las obras y en sus instancias de enseñanza y aprendizaje un pensamiento específico en torno a la praxis dramática. En este contexto, las opciones metodológicas y los paradigmas gestados al interior de los talleres de escritura teatral constituyen un capítulo insoslayable en el desarrollo de las prácticas escénicas. Desde nuestra perspectiva, las intervenciones pedagógicas desarrolladas desde la década del sesenta por autores como Osvaldo Dragún y -posteriormente- por Ricardo Monti, resultan decisivas para pensar las transformaciones y la emergencia de nuevos modelos de creación. Estas prácticas fundacionales, orientadas a perfilar nuevos paradigmas y procedimientos en materia de escritura teatral, tienen su continuidad en el desarrollo de los talleres dramatúrgicos que, ya en el contexto democrático, llevan adelante autores como el ya nombrado Dragún junto con Eduardo Rovner, Roberto Cossa, Mauricio Kartun, Ricardo Halac, Gerardo Taratuto, Carlos Somigliana, Carlos Pais, Aída Bortnik o Eugenio Griffero. Para explorar los alcances de estas experiencias, partiremos de una sintética descripción del contexto histórico en el cual estos espacios formativos emergen y se desarrollan a través de la caracterización que diversos estudios -ya canónicos- han elaborado en torno a la política cultural en dictadura, y a la situación específica del campo artístico y de sus espacios de formación. Durante este recorrido, pondremos el acento en la comprensión de estas prácticas como formas de resistencia frente a la embestida represiva del gobierno autoritario. Posteriormente, nos detendremos en la exploración de los saberes y las metodologías desplegadas en algunos talleres dramatúrgicos, a partir del testimonio de diversos participantes y asistentes. Esta indagación nos permitirá identificar la emergencia de nuevos paradigmas en torno a las dinámicas de la escritura teatral que se desarrollaron entre 1976 y los primeros años de la restauración democrática. Observaremos de forma particular las experiencias pedagógicas desarrolladas por Ricardo Monti -durante el período del gobierno de facto- y las propuestas de taller que se llevaron adelante dentro del ciclo Teatro Abierto 1985, ya en el renacimiento del orden democrácito. Desde nuestra perspectiva, ambas instancias establecieron eslabones significativos en el proceso de autonomización de los talleres de formación dramatúrgica respecto de los talleres de actuación, y contribuyeron al reconocimiento de la escritura dramática como un tipo de disciplina portadora de saberes específicos. 


\section{Espacios de formación dramatúrgica en dictadura: censura, resistencia y "cultura de las catacumbas"}

Hacia 1976, el dispositivo de censura y persecución ejecutado por la última dictadura militar instauró una profunda desarticulación en la vida cultural de la Argentina. La totalidad de los campos de producción artística, los medios masivos de comunicación y el sistema educativo en su conjunto padecieron una intervención absoluta de parte del poder represivo, dispuesto a regular la circulación de los bienes simbólicos y a disciplinar el entramado de prácticas capaces de transformar la subjetividad de la sociedad civil. La cultura fue uno de los terrenos en los cuales la vigilancia militar se impuso con mayor rigor.

Según Andrés Avellaneda (1986), el discurso autoritario ingresó a partir de 1976 en su fase de sistematización. En ella, la subordinación de la producción cultural a un orden moral y su encarnación en un territorio de pertenencia (lo católico/cristiano), en oposición a las expresiones de corte "marxista/comunista", operaron como principios rectores y argumentales para definir el ejercicio de la censura. Junto con esta dimensión represiva, integrada a un dispositivo mayor basado en la "administración de la muerte" y la "lucha contra la subversión", el autodenominado "Proceso de reorganización nacional" puso en funcionamiento una serie de mecanismos orientados a la "gestión de la vida" (Risler, 2018). De esta manera, las políticas culturales, comunicacionales y educativas tuvieron como objetivo eliminar cualquier amenaza sobre el statu quo a la vez que se orientaron a generar nuevas formas de consenso y disciplinamiento (12). La intromisión del poder autoritario sobre la totalidad de la vida cultural expandió sus redes hacia un conjunto de publicaciones y expresiones públicas que apelaron a reafirmar sus objetivos políticos y económicos frente a la sociedad civil. ${ }^{1}$

La represión afectó de manera directa las dinámicas del campo teatral, a partir del ejercicio sistemático de la censura y de la elaboración de "listas negras", estrategias centrales de la política cultural del gobierno de facto (Mogliani, 2001). En este contexto, el conjunto del campo teatral y cultural se constituyó como un espacio "doblemente fracturado" (Sarlo, 2014), marcado por la expulsión de la intervención política de los intelectuales disidentes al orden autoritario, la clausura de la esfera pública, la radical escisión del espacio cultural producto de la segregación y el exilio, y la interrupción del diálogo de los agentes intelectuales con diversas expresiones del campo popular (143). Sin embargo, frente a las prácticas de persecución y censura, la intermitente actividad teatral gestada entre 1976 y 1983 delineó de manera progresiva formas de producción y asociación que operaron como espacios de resistencia. En ellas se expresa una reelaboración del estatuto político del teatro y de su potencia transformadora. Como lo han reconocido diversos autores (Graham-Jones, 2000; Pellettieri, 2002; Dubatti, 2006) durante los años de la dictadura el teatro encuentra en la metáfora una forma privilegiada para sortear los mecanismos de censura y entablar de manera simultánea un enlace con el contexto social y político. Esta dimensión oblicua y elusiva se manifiesta en la articulación formal de los textos dramáticos y en las concepciones de la puesta en escena. Por su parte, las prácticas pedagógicas del campo teatral que se sucedieron a partir de 1976 acompañaron la reorganización de la producción cultural por fuera de los mecanismos de disciplinamiento, control y persecución ejercidos desde la política estatal. Al observar la dinámica específica de los talleres de dramaturgia durante este período, se reconocen algunos fenómenos particulares: entre la segunda mitad de la década del setenta y la restauración democrática un conjunto, los espacios privados (como el de Osvaldo Dragún, Ricardo

1. Para un estudio pormenorizado de la trama intelectual afín al "Proceso..." véase Novaro y Palermo (2003) y Álvarez (2007). Para la posición asumida por la prensa durante el período Saborido y Borrelli (2011) 
Monti o Luis Ordaz) se mantuvieron en actividad, mientras que algunos autores iniciaron su trayectoria docente. Es posible analizar estas experiencias de enseñanza en el contexto más amplio de los espacios de formación literaria y de las nuevas dinámicas de la circulación del conocimiento definidas como la "cultura de las catacumbas" (Kovadloff, 1982; Polgovsky, 2009). Según la escritora y docente Liliana Heker (1993), durante el período dictatorial la destrucción ejercida sobre las publicaciones literarias, la imposibilidad de publicación y el desconcierto de las nuevas generaciones respecto de las obras de sus pares trajo aparejado la multiplicación de talleres literarios y de espacios de formación. A esto se le sumó la necesidad de hallar nuevas formas de subsistencia económica por parte del conjunto de docentes e intelectuales que fueron expulsados de los ámbitos universitarios: "Es la conjunción de estas dos necesidades (necesidad de los nuevos posibles creadores de nuclearse y hablar de un tema en común; necesidad de los intelectuales de sobrevivir económicamente sin contaminarse con el sistema) la que instala las condiciones favorables para que los talleres se reproduzcan" (190). Al interior de esta trama semipública que describen las prácticas pedagógicas y artísticas, los talleres de dramaturgia elaboraron nuevos paradigmas de creación teatral.

\section{Ricardo Monti y el paradigma de la "imagen literaria"}

Uno de los talleres que mantuvo mayor continuidad y desarrollo en el contexto de la última dictadura militar fue el espacio de formación coordinado por Ricardo Monti. Hacia mediados de la década del setenta, Monti ya había conquistado un lugar al interior del campo teatral de Buenos Aires, con los estrenos de Una noche con el señor Magnuse Hijos (1970) e Historia Tendenciosa de la Clase Media Argentina... (1971). Durante 1976, también se desempeñó como crítico teatral en los dos últimos números de la revista Crisis.

En la escritura de Monti conviven concepciones teatrales y literarias diversas, tales como el expresionismo, el simbolismo o la reapropiación de procedimientos brechtianos. Su producción teórica también revela una enorme agudeza, abocada al desarrollo y al estudio de los procesos creativos en la escritura teatral. En particular, su comprensión de la "imagen literaria" como motor y principio de la creación dramática revela el legado del autor teatral con el movimiento "imagista", característico de la poesía de Ezra Pound y Thomas Ernest Hulme. En sus prácticas de taller, Monti afirma esta teoría y la convierte en un principio metodológico para introducir a sus alumnos en los procesos de escritura. Su conceptualización adquiere una forma nítida y reconocible en el ensayo Las imágenes en la creación literaria, escrito en 1980. Allí, orientado a pensar cuál es la materia específica que configura el trabajo del autor teatral, Monti sienta las bases para las transformaciones que se advierten en los modos de creación y enseñanza dramatúrgica a partir de la restauración democrática. Las imágenes literarias son para Monti facetas de "otro mundo", que interrumpen y profundizan el espectro de la percepción real (43). A su vez, las características que definen las imágenes de la creación artística-denominadas estéticas- se diferencian de aquellas producidas por los sueños, los recuerdos y las fantasías. Una de sus marcas distintivas refiere a la posición del sujeto: en la imagen estética el sujeto observa en su interior un acontecimiento del que no participa. Las imágenes estéticas se definen por su condición "comunicable" y poseen una cualidad sensible específica: "en un pintor la imagen previa al cuadro, la imagen proyectada interiormente que en él se forma frente al lienzo blanco, estará ya compuesta por los colores y las formas que definen su arte particular" (44). Su carácter material y sensorial vincula la producción de imágenes estéticas a la noción de estilo. El estilo, en un artista, es el "tipo particular de imágenes que lo conmueven" (44). Según Monti, la genealogía que describe el concepto de imagen encuentra una primera 
síntesis en la comprensión del poeta como individuo rodeado por figuras que viven ante él, elaborada por Nietszche en El Origen de la Tragedia. Para el pensador alemán, el concepto de metáfora no debe entenderse en términos de una mera figura retórica que el poeta ejecuta o pone en juego, sino como una imagen que flota en su interior en reemplazo de un concepto. Monti afirma, entonces, que el ejercicio del artista consiste en su capacidad para detectar, fijar, desmenuzar, interrogar y orientar el conjunto de imágenes que se le presentan (45).

La exploración de la "imagen literaria" como principio constructivo opera como un procedimiento organizativo de la propia producción de Monti pero también de su actividad docente. En sus talleres, el dramaturgo instituye un esquema de trabajo basado en la lectura de los materiales de los participantes y en la posterior observación de cada uno de ellos. Según lo expresa Víctor Winer, en esas instancias de intercambio, los participantes del taller debían abocarse a caracterizar el peso específico que las imágenes adquirían en el texto leído y comentado: se trataba de construir una reflexión "desde un lugar de imágenes y sensaciones, no desde si era bueno o malo lo leído. Al referirme a las imágenes quiero decir si eran vívidas, reconocibles, conmovedoras o no, etc." (Winer, entrevista personal, 9 de diciembre de 2020). El recuerdo de Winer permite reconocer en el trabajo sobre la imagen el núcleo específico de la creación dramatúrgica según Monti: escribir teatro se trata sobre todo de "desmenuzar", "orientar" e "interrogar" la constelación de imágenes desplegada por el texto.

El dramaturgo Jorge Huertas, asistente a los talleres de Monti hacia fines de la década del setenta junto con Winer, agrega algunas características específicas de este trabajo:

\begin{abstract}
Haberme acercado a la imagen era acercarme a cosas que yo tenía ya desde niño. No solamente es una metodología, sino que es un llamado. Es una forma de escritura que te llama, y a su vez, una forma de dramaturgo que es llamado por ese modo de escribir. La imagen es un hecho simplísimo que todos los seres humanos tenemos, y con el que todos trabajamos, vivimos y nos emocionamos, construimos pensamiento o incluso emociones (Huertas, entrevista personal, 15 de diciembre de 2020).
\end{abstract}

Para Huertas, la condición autónoma que rige la lógica de la imagen adquiere la forma de una imposición, en tanto que "la referencia a la imagen no era para describir lo que la imagen era, sino para ayudarte a extraer aquello que se te había impuesto" (Huertas, entrevista personal, 15 de diciembre de 2020). El trabajo con la imagen siembra el territorio de la producción dramatúrgica a partir del imaginario personal del escritor, habilita la revelación de un mundo íntimo que configura el relato:

Ya en el año 2015, Monti decía: "yo escucho un murmullo en lo que la persona me lee, y lo que yo trato de escuchar si en eso que me está leyendo está su alma". Esa voluntad personalísima también la veía en la imagen. En ese sentido, yo creo que fortalecía la singularidad del tipo que escribe, frente a todas las miradas posteriores (J. Huertas, entrevista personal, 15 de diciembre de 2020).

La imagen desplaza hacia un lugar secundario algunas problemáticas técnicas características de los métodos de enseñanza tradicionales, tales como la "premisa", "el conflicto", la "unidad de opuestos", o la "transición" (Egri, 1947), al instituir un modelo de escritura de carácter inductivo. Monti abre la puerta a la exploración del mundo personal del dramaturgo, de su imaginario privado, desde el cual comienza a aflorar el relato dramático. Se trata de

un movimiento de singularidad, de diversidad, de fertilidad, de primavera, desde el método inductivo (...) En el taller había discusiones: algunos planteaban "a mi me importa mucho lo que los personajes piensan" Y él decía: "bueno, en todo caso, si 
es que aparece así, es que pensás así. Tendrás un problema de contradicción con vos mismo". Eso fue extraordinario. Ese modo inductivo genera una gran confianza. En ese marco crece la creatividad. En lo deductivo vos siempre estás mirando hacia arriba a ver si encaja o no encaja en la idea (Huertas, entrevista personal, 15 de diciembre de 2020).

El trabajo sobre la imagen se despliega en el ejercicio de la forma-formante (Pareyson, 1987), en el cual el desarrollo creativo del artista, a fuerza de una exploración que avanza a tientas, construye progresivamente en su devenir un modo de hacer. La producción dramática se articula, entonces, a partir de un intentar, de un sistema de procedimientos desarrollados por medio de esbozos. Para Monti "el proceso artístico es un proceso de descubrimiento" (1980: 45).

Junto a la introducción de nuevos paradigmas de escritura, las dinámicas del taller desarrollado por Monti se integran de forma directa a las prácticas de supervivencia cultural que se llevaron adelante de manera periférica o semiprivada durante el período dictatorial. Al definir el contexto social y político de las clases, Víctor Winer afirma: "En principio aquella cultura de catacumbas significaba el desplazamiento de la cultura oficial a talleres más marginales como el de Ricardo. No marginal por la falta de riqueza del taller sino que estos encuentros solo se podían hacer lejos de la mirada de la dictadura que rechazaba cualquier desarrollo cultural que no estuviera en sus oraciones." (Winer, entrevista personal, 9 de diciembre de 2020)

El paso por el taller de Monti resulta decisivo para la configuración de las poéticas de un conjunto de dramaturgos emergentes en la segunda mitad de la década del '70, tales como Mauricio Kartun, Eduardo Rovner o los ya citados Jorge Huertas y Víctor Winer. En particular, la producción de Kartun y sus diversas etapas es ilustrativa de la novedad de estas nuevas poéticas: como consecuencia de la dinámica represiva, el dramaturgo abandona en los años del gobierno militar lo que, según su propia denominación, caracterizaba sus primeras obras, un "teatro de urgencia", marcado por un contenido político explícito. Al dejar atrás esta primer etapa, el encuentro con Monti será decisivo para aventurar la escritura de Kartun hacia nuevos territorios poéticos:

Con Chau Misterix fue raro. Fue el resultado de mi primer contacto con el taller de Ricardo Monti. Yo venía de años de práctica de una dramaturgia explícitamente política, más rigidona, y la consigna de buscar un imaginario personal me resultaba perturbadora. El detonador según recuerdo borrosamente fue el título de una película española de por entonces: El capitán Brando. Una de esas cópulas fantásticas donde dos conceptos se unen a un tercero. Mi título es un remedo de aquél. Al principio dudaba mucho. Creía tanto en las ideas por entonces que el mundo de las imágenes me parecía medio mantequita. (Kartun en Dubatti, 2006b: 8).

Más allá de los cambios experimentados en los años posteriores, la metodología de trabajo implementada por Monti y el paradigma de la imagen literaria gestado en sus talleres funda un legado. Su herencia adquiere enorme productividad en los desarrollos formativos de la posdictadura, tal como puede observarse en el ciclo Teatro Abierto 1985.

\section{La formación de nuevos autores}

Las prácticas de resistencia y de supervivencia en el teatro independiente -a través tanto de su producción específica como del desarrollo de instancias de formación en espacios privados y semiprivados- decantó en 1981 en el ciclo de Teatro Abierto, una contundente manifestación cívica y estética de abierta oposición al gobierno de facto que 
tiene a Osvaldo Dragún como su principal impulsor. ${ }^{2}$ El ciclo condensó las múltiples expresiones escénicas de enfrentamiento al régimen militar y posicionó al campo teatral como un actor relevante en la vida política del país. Producto de su enorme resonancia en la opinión pública, Teatro Abierto continuó su desarrollo durante los años de la transición y la restauración democrática, en 1982, 1983 y 1985. En su última edición, el ciclo redefinió sus coordenadas organizativas y sus objetivos, al manifestar la necesidad de extender la participación de nuevos autores y nuevos directores. Es por eso que, junto a la programación teatral, la última edición de 1985 trajo como novedad una serie de talleres de dramaturgia dirigidos a autores jóvenes y a teatristas en general. Estos encuentros e intercambios no sólo posibilitaron la aparición de nuevos autores en el panorama teatral (como Susana Pujol, Cristina Escofet, Francisco Bagalá, Luis Sáez o Patricia Zangaro) sino que también introdujeron en la práctica docente a dramaturgos como Mauricio Kartun y Eduardo Rovner, figuras decisivas para pensar el desarrollo de la enseñanza dramatúrgica en el período de posdictadura.

La estructura de cada uno de los talleres se organizó a partir de duplas pedagógicas, constituidas por un dramaturgo de trayectoria y un escritor novel. Los talleres estuvieron a cargo de Osvaldo Dragún y Eduardo Rovner; Ricardo Halac y Gerardo Taratuto; Carlos Somigliana y Carlos Pais; Aída Bortnik y Eugenio Griffero; y Roberto Cossa y Mauricio Kartun. Con una duración de entre tres y cuatro meses, los encuentros tuvieron como sede física el estudio del actor y director Roberto Durán, fallecido en 1980.

En el caso del taller desarrollado por Cossa, el encuentro con Kartun construyó una sinergia sumamente productiva, en la cual se combinaron la trayectoria profesional del primero con la experiencia de taller desarrollada por Kartun en los grupos de Monti. Según Kartun, Cossa "sabía que yo hacía taller con Monti y él nunca había hecho trabajo de taller. Por lo tanto me convocó como para organizar. Por supuesto, Tito era el que daba las devoluciones más profesionales desde su punto de vista y yo lo hacía desde mi experiencia de haber trabajado algunos años en el taller de Ricardo" (Kartun, entrevista personal, 3 de enero de 2021). El legado de Monti también resultó decisivo a la hora de definir la metodología de trabajo:

Las clases se organizaban en el trabajo tradicional de tallerear que es el que había hecho yo con Ricardo: los participantes llevaban el material y lo leían allí. Se recibía el material, se leía, se hacía una ronda de devolución de todo el grupo y luego los maestros hacían un resumen de las devoluciones que habían aparecido y su propia devolución (Kartun, entrevista personal, 3 de enero de 2021).

Al recordar su experiencia como tallerista, Kartun reconoce la incidencia que el nuevo contexto democrático adquiere en la dinámica y las expectativas formuladas en torno a los espacios de formación como una necesidad específica del campo teatral por esos años:

Lo que no hay que olvidar es que Teatro Abierto fue una iniciativa de autores. En Teatro Abierto 1985 ya no estaba ese enemigo en términos concretos, cotidianos, y la necesidad de una escritura periodística. Empezaban a aparecer otras necesidades, por ejemplo, la de la formación, que estaba muy olvidada (...) Es una diferencia abismal con lo que es hoy, por ejemplo, que simplemente en Buenos Aires debe haber 30 o cuarenta talleres y además hay tres carreras (Kartun, entrevista personal, 3 de enero de 2021).

Por su parte, Cristina Escofet fue una de las jóvenes alumnas del grupo de enseñanza coordinado por Osvaldo Dragún y Eduardo Rovner. Antes de integrarse al taller, la

2. Para una comprensión detallada del fenómeno de Teatro Abierto véase Giella (1991), Trastoy (2002), Zayas de Lima (2002), Villagra (2013) y Manduca (2017). 
dramaturga y escritora tuvo algunas participaciones como actriz en las ediciones anteriores de Teatro Abierto. Su obra Te de tías, producto del trabajo desarrollado junto a Dragún y Rovner, se estrenó en 1985 bajo la dirección de Eduardo Pavelic y continuó sus representaciones durante varios años posteriores. Según describe la autora, al igual que observamos en los talleres de Monti, la metodología de trabajo elaborada en los encuentros coordinados por Dragún también tuvieron a la imagen como punto de partida:

(Dragún y Rovner) Trabajaban con una metodología que a mi me sirvió mucho. Consistía en situarse en la imagen escénica y escribir desde el escenario, en seguir la imagen y escuchar a ese personaje al cual vos le dabas carnadura. Yo venía de trabajar como actriz y rápidamente me situé desde el escenario. El hecho de crear desde una imagen principal te lleva al lugar de la escena como punto de vista. Es una cinta de Moebius donde vos podés entrar y salir (C. Escofet, entrevista personal, 9 de diciembre de 2020).

Té de tías nace de la imagen de una gran familia pueblerina de la década del ' 50 y tematiza "lo que no debe decirse de las relaciones familiares" (Escofet, 1994: 15). En su particular tratamiento de esta temática, la producción de Escofet marca al interior de los talleres de Teatro Abierto la inclusión de nuevas discursividades orientadas al feminismo y a la comprensión de la dimensión política que anida en el interior de los vínculos privados. Según la autora, este aspecto de la obra y su tratamiento planteó una serie de discusiones:

La transgresión que yo cometí es que desfachatadamente me planté como una feminista (...) Te de tías fue una obra muy disruptiva para Teatro Abierto, porque todas las obras hablaban de la democracia y yo hablaba de conflictos familiares, y de la pobre negrita que le hicieron un aborto en escena. Yo lo que creo es que la gente se vio reflejada en el "de esto no se habla" (...) La preocupación de Chacho era que yo no cumpliera la consigna de Teatro Abierto, que consistía en escribir sobre la libertad. Y yo entendía que la libertad era también un grito de llamado hacia lo que no se dice en un contexto familiar. Yo llevé hacia otro lado la libertad (C. Escofet, entrevista personal, 9 de diciembre de 2020).

Las experiencias formativas en la última edición de Teatro Abierto producen una renovación en el campo de la producción dramatúrgica a mediados de la década del ochenta, pero también marcan el inicio de muchas experiencias docentes en el terreno de la escritura escénica y fundan un antecedente central para la proliferación de los espacios de formación que tendrán lugar de allí en adelante. La marca de su experiencia docente en Teatro Abierto como su propio tránsito como alumno de Monti definió también los fundamentos teóricos para su ejercicio docente:

La primera compilación de mi propuesta metodológica la hice sentado en un sillón con todos los apuntes que yo tenía de Monti, con un montón de libros que me interesaban, apuntes que tenía de mi primer taller que había hecho con Pedro D' Alessandro en Nuevo Teatro. Junté todo y en diez carillas armé una especie de desarrollo teórico (...) lo que estoy dando en los últimos años no es otra cosa que el desarrollo, en ejemplos y en profundización, de aquella primera compilación que hice. A partir de ahí no paré de dar clases (Kartun, entrevista personal, 3 de enero de 2021).

\section{Conclusión: "Zona de contacto" y productividad}

Los talleres de dramaturgia durante la última dictadura militar se inscriben en una transformación más amplia que experimenta la vida cultural frente al ejercicio de la censura y la persecución estatal. Según Matilde Ollier (2009), la dictadura militar 
convierte al espacio público en una zona de detención, al poner bajo sospecha la conducta de la totalidad de la población y reorganizar las condiciones que definen el uso del espacio público (81). La nueva consideración de la esfera pública, de aquello que puede o no ser enunciado, motiva también la autocensura. Los límites y las omisiones que los propios artistas ponen en juego en su producción se asienta en la peculiar ubicuidad que caracteriza al discurso represivo en la Argentina: indeterminado en sus alcances, habitado por zonas grises, en las cuales "nunca se sabe a ciencia cierta cuáles son los hechos que engendran represión" (79). Frente a las zonas de detención, Ollier describe cómo la resistencia al régimen dictatorial configura, de forma paulatina, un entrelazamiento de ex-militantes revolucionarios junto con estratos sociales que provienen de otras trayectorias políticas y culturales. Esos encuentros habilitan la emergencia de zonas de contacto, microespacios "[Que] se constituyen como privados y públicos al mismo tiempo, pues implican actividades de puertas adentro que alcanzan una mínima repercusión y contribuyen a una reflexión -menos solitaria- sobre lo privado, lo público y lo político (...)"(93). Dotadas de un valor insignificante para el régimen militar, algunas prácticas culturales como los talleres literarios y de escritura teatral, los espacios de formación actoral, los grupos de estudios privados, algunas prácticas cinematográficas, los recitales de rock y el desarrollo de las revistas "under" (Margiolakis, 2016, 2019) configuraron territorios insulares, pequeñas comunidades recortadas del sistema de regulación del espacio público y de su zona de detención, afirmando un ejercicio alternativo de la imaginación y del uso de la palabra.

Junto con esta caracterización, es posible reconocer la enorme productividad que los saberes puestos en circulación en los talleres dramatúrgicos en la dictadura y los primeros años de la restauración democrática tuvieron en el desarrollo de la escritura dramática y en la comprensión de sus procesos creativos. El concepto de "imagen literaria" acuñado por Monti, presente también en la propuesta pedagógica de Dragún en el contexto de Teatro Abierto, tendrá una enorme resonancia en la práctica docente de Mauricio Kartun y Eduardo Rovner. En Temas de dramaturgia (1992) y Una conceptiva para el dramaturgo criador (1997), Kartun afirma que el proceso de construcción dramática nace a partir de una imagen generadora. Este principio se opone a las premisas constructivas del "esquema dramático", la premisa y el plot. Del desarrollo de la imagen se despliegan para Kartun tres operaciones centrales en el proceso de creación: la sensorialidad -procedimiento base y facultad de concebir con la totalidad de los sentidos una imagen-; la indagación poética, que trabaja sobre las imágenes descubriendo en ellas figuras metonímicas, metáforas y paradojas; y, por último, la indagación dramática, revelación de las fuerzas y del conflicto que anida en los mundos imaginarios. Por su parte, Eduardo Rovner describe en su texto Imágen vs. Idea. Reflexiones acerca de la creación dramática (1989) que los caracteres esenciales que definen la obra artística no se expresan en los conceptos o las ideas, sino, justamente, en las imágenes y la forma. En este mismo artículo, el dramaturgo despliega la incidencia que las imágenes adquieren en el proceso de escritura dramática.

El desarrollo de la enseñanza en dramaturgia en la ciudad de Buenos Aires ha experimentado un crecimiento amplio y continuo desde la restauración democrática, y en los últimos años adquirió un grado de institucionalización absolutamente novedoso. Su sistema de saberes y sus sus dinámicas de trabajo alimentaron la emergencia de nuevas poéticas, de imaginarios personales, plurales y diversos, y se conjugaron con los desarrollos escénicos desplegados por las nuevas poéticas de dirección y actuación del teatro en la posdictadura. En este amplio paisaje que no deja de expandirse, las figuras de Ricardo Monti, Osvaldo Dragún, y el conjunto de docentes y talleristas aglutinados en la última edición de Teatro Abierto se erigen como los primeros referentes de una profunda transformación en las formas de creación del campo teatral que se multiplica en el presente. 


\section{Q Bibliografía}

"Avellaneda, A. (1986). Censura, autoritarismo y cultura. Buenos Aires: Centro Editor de América Latina.

"Dubatti, J. (2006a). "El teatro en dictadura y sus proyecciones en el presente" en Dubatti (Coord.) Teatro y producción de sentido político en la postdictadura. Micropoéticas III. Buenos Aires: Ediciones del CCC.

»Dubatti, J. (2006b). “Vigencia de una poética”, en Kartun, Mauricio Chau Misterix, El partener, La madonnita, La suerte de la fea. Buenos Aires: Losada.

»Dubatti, J. (2012). Cien años de teatro argentino. Buenos Aires: Biblos.

" Egri, L. (1947). Cómo escribir un drama. Buenos Aires: Bell.

»Escofet, C. (1994). Teatro Completo. Volumen 1, Buenos Aires: Torres Aguero.

" Giella, M. Á. (1991). Teatro Abierto 1981. Teatro Argentino bajo Vigilancia. Vol.I, Colección Dramaturgos Argentinos Contemporáneos, dirigida por Osvaldo PeIlettieri. Buenos Aires: Corregidor.

" Graham-Jones, J. (2000). Exorcising history: Argentine Theatre Under Dictatorship. Lewisburg: Bucknell University Press.

》 Groys, B. (2018). Volverse público: las transformaciones del arte en el ágora contemporánea. Buenos Aires: Caja Negra.

» Heker, L. (1993). “Los talleres literarios”, en Cuadernos Hispanoamericanos. 517519, Julio-septiembre, pp. 187-195.

»Kartun, M. (2015). Escritos. 1975-2015. Buenos Aires: Colihue.

"Kovadloff, S. (1982). Una cultura de las catacumbas y otros ensayos. Buenos Aires: Botella al Mar.

»Manduca, R. (2017). Teatro Abierto (1981-1983): teatro y política en la transición a la democracia. Tesis. Inédita. Disponible en: https://www.academia.edu/39513551/ Tesis_de_Licenciatura_Teatro_Abierto_1981_1983_teatro_y_pol\%C3\%ADtica_ en_la_transici\%C3\%B3n_a_la_democracia

" Margiolakis, E. (2016). La conformación de una trama de revistas culturales subterráneas durante la última dictadura cívico-militar argentina y sus transformaciones en posdictadura, tesis de doctorado. Buenos Aires: Universidad de Buenos Aires.

» Margiolakis, E. (2019). "Revistas contraculturales argentinas en dictadura y transición: debates alrededor del exilio", en Commons. Revista de Comunicación y Ciudadanía Digital, 8(2), 5-40. Disponible en: https://dx.doi.org/10.25267/ COMMONS.2019.v8.i2.01

" Mogliani, L. (2002). "Campo teatral y serie social” en Pellettieri, O. (Dir.) Historia del Teatro Argentino en Buenos Aires. El teatro actual (1976-1998). Buenos Aires, Galerna, p.81-94.

» Monti, R. (1980). “Las imágenes en la creación literaria”, en VVAA Memoración de Sigmud Freud. Buenos Aires: Trieb.

"Novaro, M., Palermo, V. (2003). La dictadura militar (1976- 1983). Del golpe de Estado a la restauración democrática. Buenos Aires: Paidós. 
»Ollier, M. M. (2009). De la revolución a la democracia. Cambios privados, públicos y políticos de la izquierda argentina. Buenos Aires: Siglo XXI.

"Pareyson, L. (1987). Conversaciones de estética. Madrid: Visor.

"Pellettieri, O. (2002). "A qué llamamos "teatro de arte" o Ciclo de Teatro Abierto" (1976-1985)", en Pellettieri, O. (Dir.) Historia del Teatro Argentino en Buenos Aires. Tomo V. Buenos Aires: Galerna. 95-98.

»Polgovsky, M. E. (2012). Cultura de las catacumbas: grupos de estudio y disidencia intelectual en el Buenos Aires de la última dictadura. Tesis. Inédita.

»Risler, J. (2018). La acción psicológica: dictadura, inteligencia y gobierno de las emociones (1955-1981). Buenos Aires: Tinta Limón Ediciones.

» Rovner, E. (1989). “Imagen vs. Idea. Reflexiones acerca de la creación dramática”, en Aa.vv. Reflexiones sobre teatro latinoaméricano del siglo XX. Buenos Aires: Galerna.

"Saborido, J., Borrelli, M. (2011). Voces y silencio. La prensa argentina y la dictadura militar (1976-1983). Buenos Aires: Eudeba.

"Sarlo, B. (2014). "El campo intelectual: espacio doblemente fracturado" en Sosnowski, Saúl (Comp.) Represión y reconstrucción de una cultura: el caso argentino. Buenos Aires, Eudeba.

»Trastoy, B. (1999). “Teatro Abierto 1981: un fenómeno social y cultural”, en Historia del Teatro Argentino en Buenos Aires. El Teatro Actual (1976-1998). Vol. V, Facultad de Filosofía y Letras (UBA). Director: Osvaldo Pelletieri. Buenos Aires: Ediciones Galerna, pp.104-111.

»Villagra, I. (2013). Teatro Abierto 1981: Dictadura y resistencia cultural. Estudio Crítico de Fuentes Primarias y Secundarias. La Plata: Al margen. 